\title{
EVALUATION OF STIMULI FOR DEVELOPMENT OF THE INDONESIAN VERSION OF VERBAL FLUENCY TASK USING RANKING METHOD
}

\author{
Donny Hendrawan ${ }^{1,2)}$ and Takeshi HATTA ${ }^{1)}$ \\ ${ }^{1)}$ Nagoya University, Japan, ${ }^{2)}$ University of Indonesia, Depok-Indonesia
}

\begin{abstract}
Several studies have asserted that the performance of verbal fluency task is strongly influenced by the socio-culture and language aspect. In the letter fluency task, participants are asked to generate words beginning with the letters F, A, S, (so-called FAS task), which has been widely used in English language. However it might not be equally suitable to other languages. Present study evaluates different kinds of letter and semantic fluency stimuli factors as part of the preparation to develop the Indonesian verbal fluency task. Results show that the letters $\mathrm{A}$ and $\mathrm{S}$ produced many different words and are positioned in the top ten ranking, which is consistent with the results of the verbal fluency research on English and Portuguese languages. However, the letter F did not meet these results. Meanwhile, for semantic fluency, animal naming seems to be the most frequently used verbal fluency stimuli in many languages. This preliminary research is expected to be a good starting point to explore many aspects of verbal fluency for Indonesian that have not been answered yet.
\end{abstract}

Key words: Indonesian, verbal fluency, letter fluency, semantic fluency

The verbal fluency task is one of the most popular neuropsychological tests applied in research and clinical settings, because it is conveniently administered and it has advantages in assessing different brain functions, which are related to psychological processes. During this task, a person is asked to produce as many words that come to his or her mind as possible, spoken or written, usually within a restricted category and a determined lapse of time. Two types of verbal fluency tasks commonly delivered are letter fluency and semantic fluency. In the letter fluency task, the participant should generate names from a specified initial letter, like F, A, and S (Borkowski, Benton, \& Spreen, 1967). While in the semantic fluency task, the participant is asked to develop names from a specified category, such as animals, fruits, vegetables, food, and other categories.

Verbal fluency has been proved to be involved in executive and word retrieval processes (Abrahams et al., 2003), memory functioning and psychomotor speed (van Beilen et al., 2004), and semantic organization (Schwartz, Baldo, Graves, \& Brugger, 2003). Moreover, this task has been also sensitive to frontal and temporal region lesions (Baldo, Schwartz, Wilkins, \& Dronkers, 2006; Troyer, Moscovitch, Vinocur, Alexander, \& Stuss, 1998), cerebellar injury (Leggio, Silveri, Petrosini, \& Molinari, 2000), Alzheimer's disease (Diaz, Sailor, Cheung, \& Kuslansky, 2004; Kitabayashi et al., 2001;

Correspondence concerning this article should be addressed to Donny Hendrawan, Nagoya University, Graduate School of Environmental Studies, Department of Psychology, Furo-cho, Chikusa-ku, Nagoya City, Aichi Prefecture, 464-8601, Japan (e-mail: donny.hendrawan@a.mbox.nagoya-u.ac.jp). Second author is now at Kansai University of Welfare Sciences, Kashiwara City, Japan. 
Salmon, Heindel, \& Lange, 1999; Sherman \& Massman, 1999), Huntington`s disease (Ho et al., 2002; Troster et al., 1998), and stroke risk (Brady, Spiro, McGlinchey-Berroth, Milberg, \& Gaziano, 2001). In addition, many researchers have investigated brain areas and verbal abilities of patients with psychiatric conditions, such as schizophrenia (Kosmidis et al., 2005; Kubota et al., 2005; Moore, Savla, Woods, Jeste, \& Palmer, 2006), depression (Fossati, Bastard Guillaume, Ergis, \& Allilaire, 2003; Okada, Okamoto, Morinobu, Yumawaki, \& Yokota, 2003; Videbech et al., 2003), and bipolar disorder (Curtis et al., 2001).

Several factors are believed to influence the performance of the verbal fluency task. An important factor that has come to our attention is the influence of cultural and linguistic backgrounds on the verbal fluency score. In research, the letters F, A, and S are the most frequently presented participants across different linguistic and ethnic backgrounds. These stimuli are not only applied for native English speakers like in the original version (Borkowski et al., 1967), but also for people from different nationalities, like Norwegians (Rodriguez-Aranda, Waterloo, Sparr, \& Sundet, 2006), Italians (Leggio et al., 2000), Swedish (Ostberg, Fernaeus, Hellstrom, Bogdanovie, \& Wahlund, 2005), French (Sauzeon, Lestage, Raboutet, N'Kaoua, \& Claverie, 2004), and Germans (Weiss et al., 2006). It is still not clear however whether or not the production of words beginning with the specific stimuli FAS is comparable across different linguistic and ethnic backgrounds (Senhorini, Amaro Júnior, deMello Ayres, de Simone, \& Busatto, 2006). For some languages, such as Spanish and Portuguese, using FAS as stimuli gave similar results as in English (Rosselli et al., 2002). In addition, the ranking of letters FAS is comparable between English and Portuguese languages, in terms of the level of difficulty to produce words (Senhorini et al., 2006). While for other languages, such as French, the amount of produced words that begin with FAS is quite different compared to English (Steenhuis \& Ostbye, 1995). Moreover, Content and colleagues (as cited in Slosman et al., 2001) argue that the letters TRPMS are more selected as French verbal fluency stimuli because of their high frequency as initial letters in the French language.

In semantic fluency task, animal naming is the most popular stimulus used in research. Nevertheless, similar to the letter fluency task, this stimulus is not yet proved to be representative of all linguistic and cultural backgrounds. Research in bilingualism reported that the number of words produced by participants when it came to animal or food items were not significantly different between French and English languages (Roberts \& Dorze, 1997, 1998). Moreover, English and Spanish speakers obtained similar scores on animal and fruit fluency (Acevedo et al., 2000). However, Spanish speakers generated the fewest number of animal names in comparison to Chinese and English speakers, while Vietnamese speakers generated the biggest number of animals names. These facts were related to the length of the words in of each these languages, animal names are longer in Spanish and shorter in Vietnamese (Kempler, Teng, Dick, Taussig, \& Davis, 1998). Therefore, linguistic and ethnic background considerations are very important in research when developing the appropriate verbal fluency task for a specific country.

The purpose of our study is to develop a valid and reliable verbal fluency test for Indonesian language speakers based on linguistic and cultural background considerations 
by adopting some previous research approaches. Specifically, we would like to examine whether or not the letters FAS and animal naming are representative enough to be used as for Indonesian language speakers. However, in order to achieve this goal, we need to identify all possible letters and categories stimuli. Therefore, as a preliminary step, this study focused on preparing stimuli of verbal fluency tasks based on the word frequency rankings beginning with Indonesian letters, from dictionaries, corpus data and other sources. These stimuli will be examined experimentally in advance in order to select representative stimuli factors of verbal fluency and will be reported in a separate article.

\section{Previous Research Approach in Identifying the Stimuli of the Verbal Fluency Task}

The first attempt to develop norms for letter fluency came from Borkowski et al. (1967). As a first step, they determined the linguistic frequency for each letter of the alphabet by assigning a score of 1 for each AA word in the Thorndike and Lorge count (TL index) and 0.5 for each A word. AA refers to a word that occurs 100 times over one million, while A refers to a word that occurs for 50 times over one million (Thorndike \& Lorge, 1944). The letters $Z$ and $X$ were omitted for further analysis since T-L frequency for these letters were zero. It means that the productivity of words related to these letters is extremely low. The remaining twenty-four letters were divided into three groups. Each group had eight orders of presentation to control practice and/or fatigue effects and each contained an equal number of easy and difficult letters, which were defined according to the weighted T-L frequency distribution.

Senhorini et al. (2006) made a list of more than three million occurrences of words in Portuguese and counted them on the basis of the number of words beginning with each letter of the alphabet. These data were gathered from extracts of conversations, monologues, lectures, interviews, and business meetings provided by researchers from the Department of Linguistics in one of the universities in Brazil. After eliminating repeated words, words that only differ from each other by their suffixes, proper nouns, and interjections, they had a rank of 25 letters. For verbal fluency experiment purposes, they chose 17 letters ranked at the top of the list of stimuli, in the following order: C, A, P, E, M, S, D, T, F, R, B, I, L, G, V, O, and N. Subsequently, they applied five stimuli for each participant, distributed among participants who have a similar level potential difficulty.

In Japan, Ito and Hatta (2002) identified the stimuli of letter fluency based on familiarity of speech frequency by using the lexical corpus of NTT database that was created by Amano and Kondo (as cited in Ito \& Hatta). After ranking the frequency of words based on forty-four initial Japanese syllables, they identified stimuli by selecting five letters with the highest familiarity and another five letters with the lowest to be observed. After which, all ten stimuli were tested with each participant.

On the other hand, information about identifying the stimuli for semantic fluency is very limited. We only found categories created by Ito and Hatta (2002), who adopted ten stimuli factors from a previous study that was conducted by Ogawa (as cited in Ito \& Hatta) and applied them to each participant. Those ten stimuli are animal, bird, fish, food, furniture, profession, spice, sport, toy, and tree. After plotting the responses of participants for each category into a curve of normal distribution, they chose the best three 
stimuli, which were animal, profession, and sport to apply to the Japanese semantic fluency task.

Based on the approaches mentioned above, following section will explain the method of identifying the Indonesian verbal fluency task.

\section{METHOD}

Several rankings were made based on the frequency of words in the dictionary and within the language familiarity data. All rankings were compared to ensure consistency in ranking of letters. First, we examined an Indonesian-Japanese Online Pocket Dictionary, which contains 4,000 words that are frequently used in daily spoken language. After eliminating repeated words, words differing from each other only by their suffixes, names of countries, acronyms, numbers, names of products, and unfamiliar words, we counted 2,182 words that could be processed further. Words with the same initial letters were grouped together and counted. Finally, we made a ranking based on the amount of words within these groups. A similar process was applied to the complete Indonesian dictionary (Kamus Besar Bahasa Indonesia, 1988) and the Indonesian Corpus Data extended by Muhadjir, Nazief, Adriani, Mangkudilaga, \& Launder (1996). However, since it was not possible to acquire the online database for the complete Indonesian dictionary, grouping and counting the words had to be done manually, which was almost impossible. For this reason, we opted for ranking the words based on the amount of dictionary pages for all words initiated by each letter instead. Fortunately, for the corpus data that were listed on the table using the Excel program (Microsoft Corp.), we succeeded to count the amount of words initiated by each letter, which amounted to 27,738 words. The last ranking was determined by the degree of familiarity with Indonesian corpus data. This data consists of 1,826,740 word occurrences and was processed by applying formula that was proposed by Borkowski et al. (1967), in which familiarity was formulated as $\mathrm{AA}+0.5^{*} \mathrm{~A}$, whereas [AA] refers to a word that occurs for 100 times in one million of word occurrences, while $[\mathrm{A}]$ refers to a word that occurs for 50 times in one million of word occurrences (Thorndike \& Lorge, 1944). After applying this data to the formula in order to attain the amount of word familiarity for each letter, we finally made our own ranking based on the degree of familiarity. However, since Muhadjir et al. found nearly two million word occurrences, while Thorndike \& Lorge only found a million, we made an additional ranking by redefining AA and A. We referred as [AA] to a word that occurs 200 times over 1,826,740, and as [A] to a word that occurs for 100 times over $1,826,740$. We then made a ranking based on a new definition of word familiarity. As a result, we have five kinds of letter rankings.

After the rankings have been made, we correlated them using the software SPSS (SPPS Inc.) in order to examine whether or not they have similar letter rankings. Borkowski et al. (1967) found out that there was a high correlation between the word fluency hierarchy and the T-L index $(r=0.80)$. The productivity of words was also correlated significantly $(r=0.74)$, related to the number of words per letter in Webster's New Collegiate Dictionary. However, the former correlation being somewhat higher may be due to the fact that both the T-L index and the word fluency score reflect associate probabilities while number of words per letter is not explicitly related to probability of occurrences. Based on these facts, we assumed that there might be a significant correlation between the dictionary ranking and word familiarity ranking.

On the other hand, for semantic verbal fluency, we adopted most stimuli factors from research conducted by Ito and Hatta (2002), except for the tree category because this stimulus seems to produce few responses. We also assumed that participant responses might be similar to the category of fruit, where the participant might simply add the word tree to the name of the fruits. Besides adopting the steps introduced by Ito and Hatta, and in order to gain better representative stimuli for Indonesian language, we tried to rank stimuli that were frequently used in semantic fluency based on 90 journals. For the next step, we compared our ranking to Japanese stimuli factors. We also considered some additional requirements in choosing our stimuli, such as clarity of interpretation by participants and likelihood to produce many responses. The cultural context was also taken into consideration. In addition, we excluded categories that only apply to a certain level of education or to a specific age. 


\section{RESULTS}

\section{Stimuli Identification for Letter Fluency}

In ranking letters based on the pocket dictionary, we found that only 24 initial letters out of 26 Indonesian letters could be applied generating words, since the letters Q and X cannot produce any words. The letter $\mathrm{S}$ was ranked first, while the letter A was ranked seventh. Which means that the letters $\mathrm{S}$ and $\mathrm{A}$ are possible factors for easy stimuli in producing words. In contrast, the letter $\mathrm{F}$ was ranked 20 of 26 letters. This means that only a small number of words starting with this letter can be generated, which categorizes it as a difficult stimuli factor of verbal fluency (see Table 1).

Table 1. Comparison Among Rankings of Letter Fluency Stimuli Candidates

\begin{tabular}{|c|c|c|c|c|c|c|c|c|c|c|}
\hline \multirow{2}{*}{ Rank } & \multicolumn{2}{|c|}{ PD } & \multicolumn{2}{|c|}{ PCD } & \multicolumn{2}{|c|}{ WFM } & \multicolumn{2}{|c|}{ FI 1} & \multicolumn{2}{|c|}{ FI 2} \\
\hline & Letter & Total & Letter & Total & Letter & Total & Letter & Total & Letter & Total \\
\hline 1 & $\mathrm{~S}$ & 253 & $\mathrm{~S}$ & 116.10 & $\mathrm{~S}$ & 3,169 & $\mathrm{~T}$ & 354.50 & $\mathrm{~T}$ & 209.00 \\
\hline 2 & $\mathrm{~K}$ & 238 & $\mathrm{~K}$ & 110.20 & $\mathrm{~K}$ & 2,742 & $\mathrm{~S}$ & 331.50 & $\mathrm{~S}$ & 205.50 \\
\hline 3 & $\mathrm{P}$ & 211 & $\mathrm{~T}$ & 98.60 & $\mathrm{~T}$ & 2,684 & $\mathrm{P}$ & 285.50 & $\mathrm{P}$ & 175.00 \\
\hline 4 & B & 194 & $\mathrm{P}$ & 83.00 & $\mathrm{P}$ & 2,478 & $\mathrm{~K}$ & 277.00 & B & 169.50 \\
\hline 5 & $\mathrm{~T}$ & 193 & B & 80.80 & B & 2,172 & B & 274.50 & $\mathrm{~K}$ & 164.00 \\
\hline 6 & M & 145 & M & 64.40 & M & 1,651 & M & 214.00 & M & 137.50 \\
\hline 7 & A & 136 & A & 59.50 & A & 1,594 & A & 203.00 & A & 125.00 \\
\hline 8 & $\mathrm{~L}$ & 126 & $\mathrm{~L}$ & 56.80 & $\mathrm{~L}$ & 1,589 & $\mathrm{~L}$ & 170.50 & $\mathrm{~L}$ & 98.00 \\
\hline 9 & $\mathrm{R}$ & 98 & $\mathrm{R}$ & 45.80 & $\mathrm{R}$ & 1,318 & $\mathrm{D}$ & 149.00 & $\mathrm{D}$ & 90.00 \\
\hline 10 & $\mathrm{D}$ & 80 & G & 43.40 & $\mathrm{D}$ & 1,265 & $\mathrm{H}$ & 104.00 & $\mathrm{~J}$ & 68.50 \\
\hline 11 & G & 80 & $\mathrm{D}$ & 39.80 & $\mathrm{G}$ & 1,216 & $\mathrm{R}$ & 98.50 & $\mathrm{H}$ & 64.00 \\
\hline 12 & $\mathrm{C}$ & 66 & $\mathrm{C}$ & 36.00 & $\mathrm{C}$ & 862 & $\mathrm{~J}$ & 94.50 & U & 58.00 \\
\hline 13 & $\mathrm{H}$ & 63 & $\mathrm{~J}$ & 29.40 & $\mathrm{H}$ & 836 & $\mathrm{U}$ & 90.50 & $\mathrm{R}$ & 53.00 \\
\hline 14 & $\mathrm{~J}$ & 57 & $\mathrm{H}$ & 27.75 & $\mathrm{~J}$ & 833 & I & 83.50 & G & 46.50 \\
\hline 15 & $\mathrm{U}$ & 48 & I & 24.00 & I & 812 & $\mathrm{G}$ & 81.50 & I & 44.50 \\
\hline 16 & $\mathrm{~N}$ & 45 & $\mathrm{U}$ & 21.90 & $\mathrm{U}$ & 576 & $\mathrm{C}$ & 62.00 & $\mathrm{C}$ & 33.00 \\
\hline 17 & I & 39 & $\mathrm{E}$ & 20.50 & $\mathrm{~N}$ & 493 & $\mathrm{~N}$ & 50.50 & $\mathrm{~N}$ & 28.00 \\
\hline 18 & W & 25 & $\mathrm{~N}$ & 16.10 & $\mathrm{E}$ & 471 & W & 34.50 & W & 19.50 \\
\hline 19 & $\mathrm{E}$ & 24 & $\mathrm{O}$ & 10.60 & $\mathrm{O}$ & 316 & $\mathrm{E}$ & 34.00 & $\mathrm{E}$ & 18.00 \\
\hline 20 & $\mathrm{O}$ & 23 & W & 8.50 & W & 261 & $\mathrm{O}$ & 29.00 & $\mathrm{O}$ & 14.50 \\
\hline 21 & $\mathrm{~F}$ & 22 & $\mathrm{~F}$ & 7.00 & $\mathrm{~F}$ & 228 & $\mathrm{~F}$ & 18.00 & $\mathrm{~F}$ & 11.50 \\
\hline 22 & $\mathrm{~V}$ & 9 & $\mathrm{Y}$ & 4.00 & $\mathrm{~V}$ & 94 & $\mathrm{Y}$ & 8.50 & $\mathrm{Y}$ & 6.00 \\
\hline 23 & $\mathrm{Y}$ & 5 & $\mathrm{Z}$ & 2.00 & $\mathrm{Y}$ & 45 & $\mathrm{~V}$ & 6.00 & $\mathrm{~V}$ & 1.00 \\
\hline 24 & Z & 2 & $\mathrm{Y}$ & 1.50 & Z & 33 & Z & 1.50 & $\mathrm{Z}$ & 1.00 \\
\hline 25 & $\mathrm{X}$ & 0 & $\mathrm{X}$ & .40 & $X$ & 0 & $X$ & .00 & $\mathrm{X}$ & .00 \\
\hline 26 & Q & 0 & Q & .10 & Q & 0 & Q & .00 & Q & .00 \\
\hline
\end{tabular}

PD Pocket Dictionary

PCD Pages of Complete Dictionary

WFM Word Frequency developed by Muhadjir

FI 1 Familiarity Index $1(\mathrm{AA}=100, \mathrm{~A}=50)$

FI 2 Familiarity Index $2(\mathrm{AA}=200, \mathrm{~A}=100)$ 
Furthermore, the results obtained through calculating the word ratio on the pages of the complete dictionary were similar to the results obtained through the word count in the pocket dictionary. The letters X and Q did generate words, but the amount of words they generated did not exceed one page per letter, which positions them at the lowest ranking. The ranking of the letters $\mathrm{F}, \mathrm{A}$, and $\mathrm{S}$ is precisely the same as the order in the pocket dictionary. Both rankings agree that the letters $\mathrm{A}$ and $\mathrm{S}$ are perceived as easy stimuli factors of verbal fluency, while the letter F is regarded as a difficult one (see Table 1).

Furthermore, the ranking based on the frequency of words of each initial letter developed by Muhadjir et al. (1996) did not show any different results with the pocket dictionary and complete dictionary rankings. Similar to the ranking of the pocket dictionary, this ranking also does not produce any words beginning with the letters $\mathrm{Q}$ and $\mathrm{X}$. Among 27,730 words, the words initiated by the letters A and S are consistently in the top ten ranking, while the letter $\mathrm{F}$ is in a lower position (see Table 1). Finally, the ranking based on familiarity or word occurrences using the T-L index also shows relatively the same result as the previous rankings (see Table 1).

In conclusion, the results shown by all rankings are very consistent. All rankings agree the letters $\mathrm{S}$ and $\mathrm{A}$ are ranked within the top ten initial letters that generate most words. On the other hand, the letter F is positioned as an initial that produces only few words. Almost all rankings, except the ranking of the complete dictionary, found that the letters $\mathrm{Q}$ and $\mathrm{X}$ as initial letters did not produce any words. In other words, the words starting by the letters $Q$ and $X$ are zero. Even though the ranking of complete dictionary found that the letters $\mathrm{Q}$ and $\mathrm{X}$ still produce words initiated by them, however their number is very small and is positioned in the last ranking in Indonesian alphabets i.e., ranking 25 and 26 out of 26. Therefore, the letters Q and X are not part of our final ranking, which leaves us with the ranking of 24 letters only.

Since the consistency among the rankings is very high, we are not surprised by the significant correlations among these rankings $(r>.96, p<.01)$. Within these correlations, we could randomly choose any of them as a final ranking (see Table 2). However, since the previous research was based word familiarity and word occurrences (Borkowski et al., 1967; Senhorini et al., 2006), we decided to replicate these methods. Consequently, we have chosen the last ranking as ours.

Another interesting finding was that there are no original Indonesian words beginning with letter $\mathrm{F}$, since most of the words starting with $\mathrm{F}$ have been borrowed from foreign languages, for example film, festival, fakta (fact), fakultas (faculty), favorit (favorite), and many other words. This could be the reason why the amounts of words starting with the letter $\mathrm{F}$ are limited.

\section{Stimuli Identification for Semantic Fluency}

The top ten rankings extracted from 90 journal articles consisted of 18 (see Table 3), of which six semantic fluency stimuli overlapped with Japanese stimuli factors (Ito \& Hatta, 2002). These categories are animal, bird, food, furniture, profession, and sport. Three of them (animal, profession, and sport) are the standardized stimuli of Japanese verbal fluency task recommended by Ito and Hatta (2002) based on the good shape of 
Table 2. Correlation Among Rankings

\begin{tabular}{lccccc}
\hline Pearson & PD & PCD & WFM & FI 1 & FI 2 \\
\hline PD & - & $.990^{* *}$ & $.989^{* *}$ & $.970^{* *}$ & $.967^{* *}$ \\
PCD & & - & $.995^{* *}$ & $.969^{* *}$ & $.963^{* *}$ \\
WFM & & & - & $.976^{* *}$ & $.969^{* *}$ \\
FI 1 & & & - & $.998^{* *}$ \\
FI2 & & & & & - \\
\hline
\end{tabular}

$* * p<.01$

PD Pocket Dictionary

PCD Pages of Complete Dictionary

WFM Word Frequency developed by Muhadjir

FI 1 Familiarity Index $1(\mathrm{AA}=100, \mathrm{~A}=50)$

FI 2 Familiarity Index $2(\mathrm{AA}=200, \mathrm{~A}=100)$

Table 3. Top Ten Stimuli Rankings of Semantic Fluency Extracted from 90 Journal Articles

\begin{tabular}{|c|c|c|}
\hline Ranking & Stimuli & $\begin{array}{l}\text { Frequency of These Stimuli Factors } \\
\text { Collected From } 90 \text { Journal Articles }\end{array}$ \\
\hline 1 & animal & 77 \\
\hline 2 & fruit & 34 \\
\hline 3 & vegetable & 17 \\
\hline 4 & furniture & 14 \\
\hline 5 & food & 12 \\
\hline 6 & transportation/vehicle & 8 \\
\hline 7 & supermarket item & 6 \\
\hline 8 & clothing & 5 \\
\hline 8 & town/city & 5 \\
\hline 8 & sport & 5 \\
\hline 8 & profession/job & 5 \\
\hline 9 & color & 4 \\
\hline 9 & car & 4 \\
\hline 9 & bird & 4 \\
\hline 10 & body part & 3 \\
\hline 10 & insect & 3 \\
\hline 10 & flower & 3 \\
\hline 10 & four-legged animal & 3 \\
\hline
\end{tabular}

normal curve distribution. This means that these stimuli were widely used in other research. Nevertheless, it is not recommended at all to choose directly the top ten rankings of semantic fluency frequently used in research as representative stimuli without confronting them with adequate scientific proof, since the best stimuli for a certain language cannot always be applied to another language. Although profession and sport are among the top ten stimuli, they only rank eighth among other stimuli that were 
Table 4. Indonesian Verbal Fluency Stimuli Factors

\begin{tabular}{cccc}
\hline Group 1 & Group 2 & Group 3 & Group 4 \\
\hline $\mathrm{T}$ & $\mathrm{S}$ & $\mathrm{P}$ & $\mathrm{B}$ \\
$\mathrm{L}$ & $\mathrm{A}$ & $\mathrm{M}$ & $\mathrm{K}$ \\
$\mathrm{H}$ & $\mathrm{U}$ & $\mathrm{D}$ & $\mathrm{J}$ \\
$\mathrm{G}$ & $\mathrm{R}$ & $\mathrm{C}$ & $\mathrm{I}$ \\
$\mathrm{N}$ & $\mathrm{W}$ & $\mathrm{E}$ & $\mathrm{O}$ \\
$\mathrm{Z}$ & $\mathrm{V}$ & $\mathrm{Y}$ & $\mathrm{F}$ \\
Profession & Fruit & Sport & Animal \\
Bird & Food & Fish & Vegetable \\
Insect & Four-legged animal & Flower & Transportation \\
Toy & Clothing & Spice & Furniture \\
\hline
\end{tabular}

extracted from 90 journal articles. Additionally, the frequency of their usage was not very significant in the previous research, compared to the stimulus animal with the ratio 5:77.

On the other hand, four other categories from Ito and Hatta (2002), such as toy, tree, fish, and spice, are not included in the top ten ranking. However, for research replication purposes, they were all kept for further analysis of Indonesian semantic fluency, except for the stimulus tree as explained above. Besides adopting nine stimuli from Japanese stimuli factors (Ito \& Hatta), we also added seven additional stimuli factors that were chosen from the top ten ranking. Those were chosen based on some requirements, such as clarity of interpretation, high productivity of responses, cultural context, and little influence from factors like education level and age. These additional stimuli are clothing, flowers, fourlegged animals, fruits, insects, transportation, and vegetables. As a result, we have 24 letter stimuli factors and 16 semantic stimuli factors that will be investigated and distributed to four different participant groups (see Table 4).

\section{DISCUSSION}

When our ranking was compared to the ranking of English version (Borkowski et.al., 1967) and the ranking of Portuguese version (Senhorini et al., 2006), we inferred that the positioning of the letters on all rankings are generally quite similar, except for the letters $\mathrm{F}$, W, C, J, and K (see Table 5). Regarding FAS positioning as verbal fluency stimuli, all rankings agree that the letters $\mathrm{A}$ and $\mathrm{S}$ are positioned at the top ten high productive items. Nonetheless, this agreement cannot be applied to the letter F, which is categorized as a high productive item for English and Portuguese, while in Indonesian language it is regarded as a less productive item.

The little frequency of words initiated by the letter $\mathrm{F}$ in Indonesian language is probably caused by the absence of this letter at the beginning of original Indonesian words, as opposed to the ones that have been borrowed from English or Arabic. Furthermore, the Unicode consortium, a non-profit organization that coordinates an 
Table 5. Comparison Among Letter Fluency Rankings

\begin{tabular}{cccc}
\hline Rank & Current Study & Borkowski & Senhorini \\
\hline 1 & $\mathrm{~T}$ & $\mathrm{~S}$ & $\mathrm{C}^{*}$ \\
2 & $\mathrm{~S}$ & $\mathrm{C}^{*}$ & $\mathrm{~A}$ \\
3 & $\mathrm{P}$ & $\mathrm{T}$ & $\mathrm{P}$ \\
4 & $\mathrm{~B}$ & $\mathrm{P}$ & $\mathrm{E}$ \\
5 & $\mathrm{~K}^{*}$ & $\mathrm{~F}$ & $\mathrm{M}$ \\
6 & $\mathrm{M}$ & $\mathrm{B}$ & $\mathrm{S}$ \\
7 & $\mathrm{~A}$ & $\mathrm{~A}$ & $\mathrm{D}$ \\
8 & $\mathrm{~L}$ & $\mathrm{~W}^{*}$ & $\mathrm{~T}$ \\
9 & $\mathrm{D}$ & $\mathrm{M}$ & $\mathrm{F}^{*}$ \\
10 & $\mathrm{~J}$ & $\mathrm{D}$ & $\mathrm{R}$ \\
11 & $\mathrm{H}$ & $\mathrm{H}$ & $\mathrm{B}$ \\
12 & $\mathrm{U}$ & $\mathrm{R}$ & $\mathrm{I}$ \\
13 & $\mathrm{R}$ & $\mathrm{L}$ & $\mathrm{L}$ \\
14 & $\mathrm{G}$ & $\mathrm{G}$ & $\mathrm{G}$ \\
15 & $\mathrm{I}$ & $\mathrm{E}$ & $\mathrm{V}$ \\
16 & $\mathrm{C}^{*}$ & $\mathrm{~N}$ & $\mathrm{O}$ \\
17 & $\mathrm{~N}$ & $\mathrm{O}$ & $\mathrm{N}$ \\
18 & $\mathrm{~W}$ & $\mathrm{I}$ & $\mathrm{H}$ \\
19 & $\mathrm{E}$ & $\mathrm{U}$ & $\mathrm{Q}$ \\
20 & $\mathrm{O}$ & $\mathrm{K}^{*}$ & $\mathrm{~J}$ \\
21 & $\mathrm{~F}$ & $\mathrm{Y}$ & $\mathrm{U}$ \\
22 & $\mathrm{Y}$ & $\mathrm{V}$ & $\mathrm{Z}$ \\
23 & $\mathrm{~V}$ & $\mathrm{~J}$ & $\mathrm{~W}$ \\
24 & $\mathrm{Z}$ & & \\
25 & & & $\mathrm{Z}$ \\
\hline
\end{tabular}

* The rank order of these letters is extremely different in Indonesian (current study) from English (Borkowski) and Portuguese (Senhorini)

industry standard, allows computers to consistently represent and manipulate text expressed in most of the world writing systems, does not record the letter $\mathrm{F}$ as an original letter among six kinds of popular Indonesian ethnic languages. Nevertheless, although the letter is adopted from foreign alphabets, Indonesian people do not seem to have any significant problem pronouncing words containing this letter. As a matter of fact, even people from specific ethnics, i.e., Sundanese and Balinese, who pronounce the letter $\mathrm{F}$ as $\mathrm{P}$ in non-native words (for example, film is pronounced as pilm, forum as porum, etc.), can pronounce those words quite accurately with moderate effort. On the other hand, compared to Indonesian people, the Japanese seem to need more effort to pronounce a non-native word, which is not popular among Japanese syllables. They seem to have problems differentiating the letters $\mathrm{R}$ and $\mathrm{L}$ for example.

Why is it that the Indonesians pronounce non-native unfamiliar words more accurately than the Japanese? We assumed that by adopting the letter F, which is notably 
from another language, to be part of the Indonesian alphabet, it would enhance speakers' sensitivity in discriminating between this letter and indigenous ones. As a result, Indonesian speakers can maintain a phonological contrast between the letters $\mathrm{F}$ and $\mathrm{P}$ for both native and non-native words. On the other hand, Japanese language only incorporates the letter $\mathrm{R}$ to the detriment of $\mathrm{L}$ in its syllable system, so that is why Japanese lacks an $/ r /-/ / /$ contrast. Consequently, Japanese native speakers, especially adults, have great difficulty in discriminating between words containing English letters R and L, even when hearing native American speeches (Goto, 1971).

There are two important factors which influence the degree of sensitivity in perceiving non-native languages. The first factor is related to the intensity of conversational experience in a specific non-native language. The more one is exposed to the non-native language, which has a difference in phonological properties compared to his/her own native language, the better he/she could differentiate between those properties. Goto (1971) argued that Japanese speakers who have had little conversational experience with native English speakers tend to be feeble in discriminating the letters $\mathrm{R}$ and L. The second factor is connected to the exposure time to a specific language. The younger the people are confronted to the practice of auditory discrimination in speech and listening are, the more accurately they discriminate among the letter pronunciation (Goto, 1971). Even at the early age of six months, the phonetic perception of infants can be altered by their exposure to a specific language (Kuhl, Williams, Lacerda, Stevens, \& Lindblom, 1992). After this age, the ability to discriminate the non-native phonemes starts to decline (Tsushima et al., 1994). We are therefore assuming that Indonesians who have difficulties differentiating between $\mathrm{F}$ and $\mathrm{P}$, could be subject to one of - or bothfactors mentioned above. This is mostly due to the fact that many Indonesians learn their ethnic language first, and they only learn Indonesian once they start going to school, or even later on.

Another letter that is in the same position as $\mathrm{F}$ when it comes to the reversed English ranking is the letter W. Even though the amount of words starting with W slightly outnumbers the amount of words starting with F, both are still in the same lower category. Like words beginning with F, many words beginning with $\mathrm{W}$ have been adopted from foreign languages, such as Arabic and Sanskrit. Nevertheless, since according to Unicode standard, all Indonesian ethnic languages already have the letter $\mathrm{W}$ in their phoneme, Indonesians do not seem to have any difficulty in perceiving this letter, neither orally, nor auditory. Moreover, the accuracy in perceiving $\mathrm{W}$ is enhanced by the fact Javanese, one of the Indonesian ethnic languages, originates from Sanskrit (Haudricourt, 1965). Consequently, Indonesian words that have been adopted from Sanskrit are very similar to Javanese words.

The letter $\mathrm{C}$ as an initial also produces a small number of Indonesian words, and has a reversed ranking according to Borkowski et al. (1967) and Senhorini et al. (2006). However, unlike the letter $\mathrm{F}$, which produces words that are mostly adopted from foreign languages, the letter $\mathrm{C}$ produces many original Indonesian words. We assumed that the different number of words between Indonesian and English are more likely due to the multi-sound generated by the letter $\mathrm{C}$ when attached in different English words. For 
example, not only does the letter $\mathrm{C}$ in English sound as $\mathrm{C}$ (chain, chest, and chocolate), it can also sound as $\mathrm{K}$ (call, clear, and cool), and $\mathrm{S}$ (cell, cereal, and cerebral). As a result, there is a great deal of English words starting with $\mathrm{C}$. On the contrary, the letter $\mathrm{C}$ in Indonesian only produces one sound, i.e. $\mathrm{C}$, which means that the amount of words starting with $\mathrm{C}$ in Indonesian are fewer than in English.

Unlike the letters F, C, and W, which generate only a limited amount of Indonesian words, the letters $\mathrm{K}$ and $\mathrm{J}$ can generate many Indonesian words. In our opinion, the productions of words starting with these letters are quite limited in English because other letters can produce similar sounds. For example, the sound $\mathrm{K}$ is not only produced by the letter $\mathrm{K}$ itself (kiss, kid, kill, etc), but also by the letter $\mathrm{C}$ (call, could, come, and so on). Along the same argument, the sound produced by the letter $\mathrm{J}$ can be produced by the letter $\mathrm{J}$ itself (jealous, jump, jet, etc.) as well as by the letter $\mathrm{G}$ (gentle, gorgeous, genius, and so on). Unlike in English, the letters $\mathrm{K}$ and $\mathrm{J}$ in Indonesian can produce a bigger amount of words, simply because the sounds that these letters create are unique to these letters, and cannot be produced by any other letters, or letter combinations.

Apparently, among semantic fluency tasks, the use of animal naming as a stimulus is more common in research than other stimuli. Among 90 studies on semantic fluency, 77 apply animal naming as a stimulus. Moreover, Ito and Hatta (2002) have found that the distribution of participant responses in reacting to animal naming had given a very good result in relation to the normal curve pattern. However, whether or not this stimulus could also be applied for Indonesian participants will continue to be under question, until this research gets past the theoretical work frame, and is applied in practice. Other stimuli, like the letters FAS in verbal fluency also need to be tested experimentally. Although the letters $\mathrm{A}$ and $\mathrm{S}$ seem to have the same positioning in Indonesian language as in other languages, however this does not guarantee that stimulus is suitable for Indonesians, not until stimulus is experimentally proven.

Finally, this preliminary study has helped us organize the different verbal fluency stimuli factors into groups that did not exist previously. This will make it easier in the future to conduct research and determine the best verbal fluency stimuli. This research is also expected to pave the way for exploring many more aspects of Indonesian verbal fluency, such as establishing norms that deal with age, gender, and education, switching and clustering patterns, exploring brain activities during the tasks, and many other important issues.

\section{REFERENCES}

Abrahams, S., Goldstein, L. H., Simmons, A., Brammer, M. J., Williams, S. C. R. et al., 2003. Functional magnetic resonance imaging of verbal fluency and confrontation naming using compressed image acquisition to permit overt responses. Human Brain Mapping, 20, 29-40.

Acevedo, A., Loewenstein, D. A., Barker, W. W., Hardwood, D. G., Luis, C., Bravo, M. et al., 2000. Category fluency test: Normative data for English- and Spanish-speaking elderly. Journal of the International Neuropsychological Society, 6, 760-769.

Baldo, J. V., Schwartz, S., Wilkins, D., \& Dronkers, N. F. 2006. Role of frontal versus temporal cortex in verbal fluency as revealed by voxel-based lesion symptom mapping. Journal of the International 
Neuropsychological Society, 12, 896-900.

Borkowski, J. G., Benton, A. L., \& Spreen, O. 1967. Word fluency and brain damage. Neuropsychologia, 5, 135-140.

Brady, C. B., Spiro, A., McGlinchey-Berroth, R., Milberg, W., \& Gaziano, J. M. 2001. Stroke Risk Predicts Verbal Fluency Decline in Healthy Older Men: Evidence From the Normative Aging Study. The journals of Gerontology. Series B, Psychological Sciences and social sciences, 56, 340-346.

Curtis, V. A., Dixon, T. A., Morris, R. G., Bullmore, E. T., Brammer, M. J., Williams, S. C. R. et al., 2001. Differential frontal activation in schizophrenia and bipolar illness during verbal fluency. Journal of Affective Disorders, 66, 111-121.

Diaz, M., Sailor, K., Cheung, D., \& Kuslansky, G. 2004. Category size effects in semantic and letter fluency in Alzheimer's patients. Brain and Language, 89, 108-114.

Fossati, P., Bastard Guillaume, L., Ergis, A.-M., \& Allilaire, J.-F. 2003. Qualitative analysis of verbal fluency in depression. Psychiatry Research, 117, 17-24.

Goto, H. 1971. Auditory perception by normal Japanese adults of the sounds "L" and "R". Neuropsychologia, 9, 317-323.

Haudricourt, A. 1965. Problems of Austronesian comparative philology. Lingua, 14, 315-329.

Ho, A. K., Sahakian, B. J., Robbins, T. W., Barker, R. A., Rosser, A. E., \& Hodges, J. R. 2002. Verbal fluency in Huntington's disease: A longitudinal analysis of phonemic and semantic clustering and switching. Neuropsychologia, 40, 1277-1284.

Ito, E., \& Hatta, T 2002. Development of the verbal fluency test for Japanese. Studies in Informatics \& Science, 15, 81-96.

Kamus besar bahasa Indonesia [Indonesian dictionary], (1st ed.). 1988. Jakarta: Balai Pustaka.

Kempler, D., Teng, E. L., Dick, M., Taussig, I. M., \& Davis, D. S. 1998. The effects of age, education, and ethnicity on verbal fluency. Journal of the International Neuropsychological Society, 4, 531-538.

Kitabayashi, Y., Ueda, H., Tsuchida, H., Iizumi, H., Narumoto, J., Nakamura, K. et al., 2001. Relationship between regional cerebral blood flow and verbal fluency in Alzheimer's disease. Psychiatry and Clinical Neurosciences, 55, 459-463.

Kosmidis, M. H., Bozikas, V. P., Vlahou, C. H., Kiosseoglou, G., Giaglis, G., \& Karavatos, A. 2005. Verbal fluency in institutionalized patients with schizophrenia: Age-related performance decline. Psychiatry Research, 134, 233-240.

Kubota, Y., Toichi, M., Shimizu, M., Mason, R. A., Coconcea, C. M., Findling, R. L. et al., 2005. Prefrontal activation during verbal fluency tests in schizophrenia - a near-infrared spectroscopy (NIRS) study. Schizophrenia Research, 77, 65-73.

Kuhl, P. K., Williams, K. A., Lacerda, F., Stevens, K. N., \& Lindblom, B. 1992. Linguistic experience alters phonetic perception in infants by 6 months of age. Science, 255, 606-608.

Leggio, M. G., Silveri, M. C., Petrosini, L., \& Molinari, M. 2000. Phonological grouping is specifically affected in cerebellar patients: a verbal fluency study. Journal of Neurology, Neurosurgery \& Psychiatry, 69, 102-106.

Moore, D. J., Savla, G. N., Woods, S. P., Jeste, D. V., \& Palmer, B. W. 2006. Verbal fluency impairments among middle-aged and older outpatients with schizophrenia are characterized by deficient switching. Schizophrenia Research, 87, 254-260.

Muhadjir, Nazief, B. A. A., Adriani, M., Mangkudilaga, K., \& Launder, M. R. M. T. 1996. Frekuensi kosakata bahasa Indonesia [The vocabulary frequency of Indonesian language]. Depok: Fakultas Sastra Universitas Indonesia.

Okada, G., Okamoto, Y., Morinobu, S., Yumawaki, S., \& Yokota, N. 2003. Attenuated left prefrontal activation during a verbal fluency task in patients with depression. Neuropsychobiology, 47, 21-26.

Ostberg, P., Fernaeus, S. E., Hellstrom, A., Bogdanovie, N., \& Wahlund, L. O. 2005. Impaired verbal fluency: a sign of mild cognitive impairment. Brain and Language, 95, 273-279.

Roberts, P. M., \& Dorze, G. L. 1997. Semantic organization, strategy use, and productivity in bilingual semantic verbal fluency. Brain and Language, 59, 412-449.

Roberts, P. M., \& Dorze, G. L. 1998. Bilingual aphasia: semantic organization, strategy use, and productivity in semantic verbal fluency. Brain and Language, 65, 287-312.

Rodriguez-Aranda, C., Waterloo, K., Sparr, S., \& Sundet, K. 2006. Age-related psychomotor slowing as an important component of verbal fluency. Journal of Neurology, 253, 1414-1427. 
Rosselli, M., Ardila, A., Salvatierra, J., Marquez, M., Matos, L., \& Weekes, V. A. 2002. A cross-linguistic comparison of verbal fluency tests. International Journal of Neuroscience, 112, 759-776.

Salmon, D. P., Heindel, W. C., \& Lange, K. L. 1999. Differential decline in word generation from phonemic and semantic categories during the course of Alzheimer's disease: Implications for the integrity of semantic memory. Journal of the International Neuropsychological Society, 5, 692-703.

Sauzeon, H., Lestage, P., Raboutet, C., N'Kaoua, B., \& Claverie, B. 2004. Verbal fluency output in children aged 7-16 as a function o the production criterion: Qualitative analysis of clustering, switching processes, and semantic network exploitation. Brain and Language, 89, 192-202.

Schwartz, S., Baldo, J., Graves, R. E., \& Brugger, P. 2003. Pervasive influence of semantics in letter and category fluency: A multidimensional approach. Brain and Language, 87, 400-411.

Senhorini, M. C. T., Amaro Júnior, E., de Mello Ayres, A., de Simone, A., \& Busatto, G. F. 2006. Phonemic fluency in Portuguese-speaking subjects in Brazil: ranking of letters. Journal of Clinical and Experimental Neuropsychology, 28, 1191-1200.

Sherman, A. M., \& Massman, P. J. 1999. Prevalence and Correlates of Category Versus Letter Fluency Discrepancies in Alzheimer's Disease. Archives of Clinical Neuropsychology, 14, 411-418.

Slosman, D. O., Ludwig, C., Zerarka, S., Pellerin, L., Chicherio, C., de Ribaupierre, A. et al., 2001. Brain energy metabolism in Alzheimer`s disease: ${ }^{99 \mathrm{~m}} \mathrm{Tc}-\mathrm{HMPAO}$ SPECT imaging during verbal fluency and role of astrocytes in the cellular mechanism of ${ }^{99 \mathrm{~m}} \mathrm{Tc}-\mathrm{HMPAO}$ retention. Brain Research Reviews, 36, 230-240.

Steenhuis, R. E., \& Ostbye, T. 1995. Neuropsychological test performance of specific diagnostic groups in the Canadian study of health and aging (CSHA). Journal of Clinical and Experimental Neuropsychology, 17, 773-785.

Thorndike, E. L., \& Lorge, I. 1944. The Teacher's Word Book of 30.000 words. New York: Teachers College Columbia University.

Troster, A. I., Fields, J. A., Testa, J. A., Paul, R. H., Blanco, C. R., Hames, K. A. et al., 1998. Cortical and subcortical influences on clustering and switching in the performance of verbal fluency tasks. Neuropsychologia, 36, 295-304.

Troyer, A. K., Moscovitch, M., Vinocur, G., Alexander, M. P., \& Stuss, D. 1998. Clustering and switching on verbal fluency: the effects of focal frontal- and temporal-lobe lesions. Neuropsychologia, 36, 499504.

Tsushima, T., Takizawa, O., Sasaki, M., Shiraki, S., Nishi, K., Kohno, M. et al., 1994. Developmental changes in perceptual discrimination of non-native speech contrasts by Japanese infants (Technical Report of IEICE SP94-31 No. 166). Tokyo: The Institute of Electronics Information and Communication Engineers.

van Beilen, M., Pijnenborg, M., van Zomeren, E. H., van den Bosch, R. J., Withaar, F. K., \& Bouma, A. 2004. What is measured by verbal fluency tests in schizophrenia? Schizophrenia Research, 69, 267-276.

Videbech, P., Ravnkilde, B., Kristensen, S., Egander, A., Clemmensen, K., Rasmussen, N. A. et al., 2003. The Danish PET/depression project: poor verbal fluency performance despite normal prefrontal activation in patients with major depression. Psychiatry Research: Neuroimaging, 123, 49-63.

Weiss, E. M., Ragland, J. D., Brensinger, C. M., Bilker, W. B., Deisenhammer, E. A., \& Delazer, M. 2006. Sex differences in clustering and switching in verbal fluency tasks. Journal of the International Neuropsychological Society, 12, 502-509. 